\title{
Sobre a Nudez Forte do Núcleo, o Manto Díáfano da Nuvem ELECTRÓNICA: As MemórIAS DUM ÁtOMO
}

\author{
Mário Berberan e Santos \\ Centro de Química-Física Molecular, Instituto Superior Técnico, Universidade de Lisboa \\ berberan@ist.utl.pt
}

\begin{abstract}
D iscutem-se o conteúdo e o contexto cultural das Memórias dum Átomo, singular romance oitocentista, dando-se especial atenção aos aspectos químicos e a possíveis fontes de inspiração.
\end{abstract}

\section{As Memórias dum Átomo e a Química contemporÂNeA}

O título Memórias dum Átomo evoca imediatamente, nos apreciadores de Eça de Queirós, - e somo-lo quase todos -, o livro inacabado de João da Ega, descrito em Os Maias (1888) [1]. Alguns excertos desta obra foram publicados no Química há já muitos anos [2], numa secção chamada Antologia [3].

As Memórias dum Átomo, romance dentro de um romance, são, sem paradoxo, uma obra inexistente, de um autor imaginário, sobre um protagonista impossível:

“(...) Devia ser uma epopeia em prosa, como ele [João da Ega] dizia, dando, sob episódios simbólicos, a história das grandes fases do Universo e da Humanidade. Intitulava-se Memórias dum Átomo, e tinha a forma duma autobiografia. Este átomo (o átomo do Ega, como se lhe chamava a sério em Coimbra [entre os condiscípulos]), aparecia no primeiro capítulo, rolando ainda no vago das Nebulosas primitivas: depois vinha embrulhado, faísca candente, na massa de fogo que devia ser mais tarde a Terra: enfim, fazia parte da primeira folha de planta que surgiu da crosta ainda mole do globo. Desde então, viajando nas incessantes transformações da substância, o átomo do Ega entrava na rude estrutura do Orango, pai da humanidade - e mais tarde vivia nos lábios de Platão. Negrejava no burel dos santos, refulgia na espada dos heróis, palpitava no coração dos poetas. Gota de água nos lagos de Galileia, ouvira o falar de Jesus, aos fins da tarde, quando os apóstolos recolhiam as redes; nó de madeira na tribuna da Convenção, sentira o frio da mão de Robespierre. Errara nos vastos anéis de Saturno; e as madrugadas da terra tinham-no orvalhado, pétala resplandecente de um dormente e lânguido lírio. Fora omnipresente, era omnisciente. Achando-se finalmente no bico da pena do Ega, e cansado desta jornada através do Ser, repousava - escrevendo as suas Memórias... (...)”.

As poucas linhas transcritas, para além de todo o seu sabor literário e de época, indicam-nos que Eça de Queirós conhecia as teorias de Kant e de Laplace (séc. XVIII) sobre a formação do sistema solar, o darwinismo (On the Origin of Species by Means of Natural Selection, 1859; The Descent of Man, and Selection in Relation to Sex, 1871) e, também, em termos gerais, a teoria atómica. Esta última, recorde-se, só foi plenamente estabelecida e aceite na primeira década do séc. XX [4,5], sendo os conceitos de núcleo e de nuvem electrónica posteriores (segunda e terceira décadas desse século, respectivamente) $[5,6]$.

N’Os Maias há também uma menção explícita à ligação química, fazendo-se o paralelo entre a amizade e a união dos «átomos em gancho de Descartes». A imagem, embora sugestiva, poderá parecer antiquada para o ano de 1888, se levada à letra, mas ainda aparecia num livro de Física alemão que o jovem Werner Heisenberg (1901-1976) leu em 1919, e o impressionou muito desfavoravelmente: «se os átomos são configurações representáveis tão grosseiramente (...), se têm uma forma complicada a ponto de possuírem até ganchos e colchetes, é impossível que sejam os mais pequenos, indivisíveis elementos da matéria.» [7].

\section{A LITERATURA CIENTÍFICA POPULAR NA SEGUNDA METADE DO SÉCULO XIX}

O grande progresso da Ciência e da Técnica no século dezanove - principalmente na sua segunda metade - foi acompanhado por uma abundante literatura de divulgação (periódicos e livros), descrevendo e exaltando, quase euforicamente, as novas descobertas e invenções, e respectivas consequências sociais e filosóficas, invariavelmente positivas [8-10]. Várias obras, notáveis pelo conteúdo e pela qualidade gráfica, tiveram tiragens elevadas em sucessivas edições, e ainda hoje se encontram no mercado do livro antigo, sem grande dificuldade, exemplares, por exemplo das obras de Louis Figuier (1819-1894) e de Camille Flammarion (1842-1925) - a Astronomie Populaire deste último, com $1 .^{\text {a }}$ ed. em 1879, ultrapassava já os 100.000 exemplares em 1900. Algumas obras destes autores foram traduzidas para português [11], designadamente As Grandes Invenções, de Louis Figuier (Porto e Braga, 1873, tradução do original francês de 1861), Figura 1.

\section{O Primo Basílio (1878) começa precisamente assim:}

"Tinham dado onze horas no cuco da sala de jantar. Jorge fechou o volume de Luís Figuier que estivera folheando devagar (...)”. 


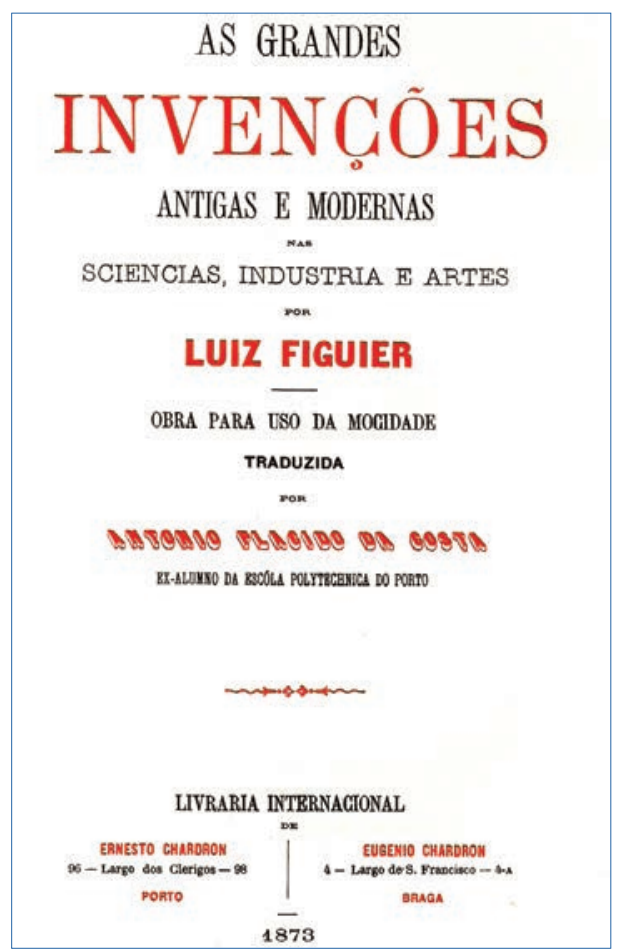

Figura 1 - Frontispício de As Grandes Invenções (Porto e Braga, 1873), de Louis Figuier, tradução do original francês de 1861, pelo médico e professor universitário portuense António Plácido da Costa (1848-1916)

Sendo Jorge engenheiro de minas (pela Escola Politécnica de Lisboa), é, no entanto, de presumir que lesse Figuier no original.

Outras obras de vulgarização científica, pelo contrário, tornaram-se raridades. É o caso de Histoire d'un atome de carbone, depuis l'origine des temps jusqu'à ce jour (Librairie de Delahaye, Paris, 1864), livro não citado sequer em [8-10], de dois autores desconhecidos e quase anónimos (assinam B. de B. e A. C.), Figura 2, um pequeno in-12 $2^{\circ}$ de uma centena de páginas, de que restarão muito poucos exemplares (de uma tiragem já de si limitada).

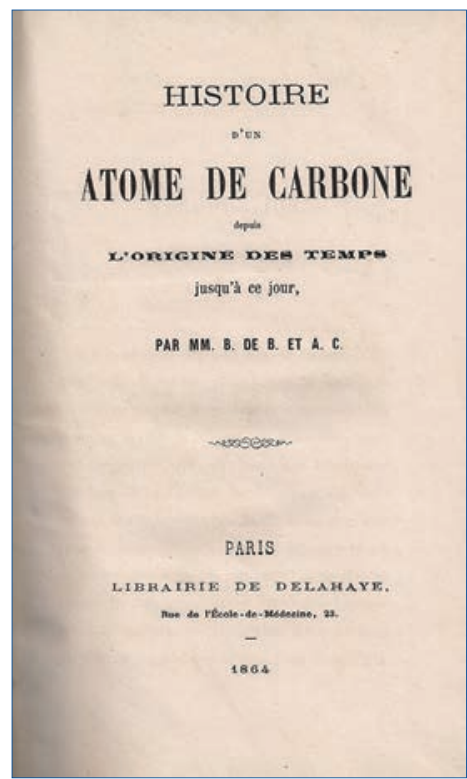

Figura 2 - Frontispício de História de um átomo de carbono, da origem dos tempos até aos nossos dias, pelos senhores B. de B. e A. C. (Paris, 1864). O segundo ditou a obra ao primeiro.
Para além das obras de «ciência popular», surgiram nesta época os romances científicos de aventuras, cujo pioneiro e expoente máximo foi Júlio Verne (1828-1905; iniciou a sua ascensão literária em 1863, com Cinco semanas em balão, para logo descer às profundezas do planeta, com Viagem ao Centro da Terra, em 1864 [12]).

A própria literatura «séria» foi permeável à «cultura científica emergente», como hoje se diria. Essa influência sobre os autores veio não só directamente do quotidiano e de conhecimentos pessoais no mundo da ciência e da engenharia, mas ainda de fontes escritas, das quais as mais acessíveis a um homem de letras seriam precisamente os livros e os artigos de divulgação. Há, em particular, registo de a Histoire d'un atome de carbone ter sido consultada por Flaubert, em 1872 [13], certamente tendo em vista Bouvard et Pécuchet (publicado postumamente, inconcluso, em 1881), romance onde se critica o saber enciclopédico mas superficial, com referências directas à Química num dos capítulos, e para o qual o escritor leu centenas de livros - fala-se em mais de mil e quinhentos -, muitos dos quais de divulgação científica [10].

\section{ESTILO AUTOBIOGRÁFICO E ANTROPOMORFISMO}

A forma escolhida por Eça/Ega para a «História das grandes fases do Universo e da Humanidade», a autobiografia de um átomo, introduz um elemento de permanência na mudança, elemento esse que, dada a perspectiva racionalista, tinha de ser material. A narrativa na primeira pessoa transforma uma descrição árida e duvidosa num testemunho directo e convincente («eu estive lá») e, até, quase íntimo, se acompanhado de comentários e confidências. Um átomo que fala é, além disso, um recurso estilístico que surpreende e diverte o leitor, e o predispõe a acompanhar o autor numa longa viagem que, de outra forma, poderia ser uma «seca» interminável [14].

O antropomorfismo é tão antigo como o ser humano, com manifestações primitivas como o animismo e a idolatria, e todos passámos por ele na infância. Muitos livros para crianças (e peças de teatro, filmes, etc.), tanto lúdicos como pedagógicos, recorrem por isso à personificação. Quem não se enterneceu com a história do soldadinho de chumbo (H. C. Andersen, 1838), que era aliás de estanho [15]? Também em várias obras oitocentistas de divulgação científica se utilizou a personificação, da mencionada Histoire d'un atome de carbone à satírica Flatland (Londres, 1884), de Edwin Abbott, em que a figura de estilo é levada ao limite, pois é aplicada a conceitos geométricos, incluindo o ponto! Mais extremo do que isto, só a personificação do conjunto vazio... que, por uma associação de ideias perversa mas irreprimível, faz pensar em certas figuras públicas, umas, meros ectoplasmas do Conselheiro Acácio e do grande Pacheco, que nos continuam a assombrar, e outras, tipos novos a que Eça foi poupado, mas bem mereciam a atenção da sua pena refinada.

\section{A esqueCida Histolre d'un ATOME de CARBONE}

Voltando à Histoire d'un atome de carbone, livrinho denso e sem figuras, começa-se por uma introdução em que o au- 
tor (o enigmático B. de B., que não consta dos dicionários de pseudónimos oitocentistas [16]) declara ter-se limitado a escrever o que lhe fora ditado por um dos átomos de carbono do seu cérebro (obviamente o outro autor, A. C.), átomo esse que pressentia ir separar-se em breve do «infeliz dono da forma material de que fazia momentaneamente parte». Trata-se de uma narrativa que segue o programa indicado por Eça, embora com ênfase na «história química da Terra», e em que o átomo conta as suas peripécias, desde a nebulosa primordial com movimentos turbilhonares, da qual a Terra nasce, até à incorporação no corpo do escritor, que o átomo acaba por abandonar no fim na história.

Logo nas primeiras páginas, o átomo de carbono define-se: «para mim, átomo indestrutível, o tempo não existe; só o posso apreciar pelas metamorfoses que vou sofrendo, à medida que entro em diferentes combinações de que sou um dos elementos.» Depois da nebulosa, o átomo de carbono surge-nos numa Terra ígnea e sem oxigénio atmosférico, com uma superfície em que correm regatos de ferro líquido, e em cujo interior, sujeito a pressões enormes, acaba por cristalizar, juntamente com vários irmãos, na forma de diamante (p. 11). Após muito tempo, a colisão de um corpo celeste com a Terra altera bruscamente o seu eixo de rotação e oxigena a atmosfera (sabe-se hoje que não foi nada assim - a deriva dos continentes e a acção dos primeiros seres vivos não eram conhecidas), levando à formação de água (p. 13). Muito depois, um segundo choque colossal altera de novo a orientação do eixo de rotação, provocando ao mesmo tempo falhas profundas na crusta que permitem a subida do átomo à superfície, e a sua combinação com o oxigénio atmosférico para formar «ácido carbónico» (dióxido de carbono) (p. 14). A molécula é mais tarde absorvida por uma das primeiras formas vegetais marinhas, início de um longo e fastidioso trajecto pela cadeia alimentar, em que o átomo vai passando por plantas e animais inferiores, incluindo uma trilobite (p. 16). Nesta, e pela primeira vez depois de muitos milhões de anos, sente o efeito da radiação solar, ao fazer parte do humor vítreo de um dos olhos primevos. Passam-se os séculos, e acaba por se combinar com quatro átomos de hidrogénio, para formar o «protocarbureto de hidrogénio» (metano), numa «união poligâmica» [17] duradoura (p. 23).

Evitemos ao leitor o fio completo da narrativa, mesmo abreviado. Diga-se, apenas, que a primeira figura histórica de que o átomo faz (fugazmente) parte é Cleópatra, na qual entra incorporado numa molécula de veneno, quando a monarca se suicida, ao fazer-se picar, no seio descoberto, por uma áspide (p. 71), episódio consagrado por Shakespeare mas cuja veracidade é duvidosa. O átomo transpõe depois o Mediterrâneo, e é sucessivamente parte dos colares de uma patrícia romana e de uma cortesã inglesa, antes de integrar o pó de carvão usado pelo franciscano Roger Bacon para produzir pólvora (p. 74), e de, vários séculos depois, ir parar ao cérebro de B. de B., após ser ingerido numa maçã, durante a Páscoa de 1863. E hoje, por onde andará o «judeu errante» [18] microscópico? Talvez esteja mesmo debaixo do seu nariz, caro leitor, no papel ou na tinta do Química, ou até, quem sabe, tenha neste preciso instante começado a ouvir uma vo- zinha interior, débil mas imperiosa, sussurrando um post-scriptum...

Nas últimas páginas, o átomo discorre sobre o significado da existência mas, muito apropriadamente, não passa de um nível filosófico elementar. Afirma, por fim, que a «consciência do dever cumprido» é a «única alegria certa da existência», deixando, como «supremo conselho» de despedida, «nunca falhar uma obrigação». Referir-se-ia este cidadão do Universo à obediência às leis físicas e químicas? Mas os átomos, que se saiba, não possuem livre-arbítrio...

Terá o Eça de Queirós estudante de Direito conhecido a recém-publicada Histoire d'un atome de carbone em Coimbra, altura em que poderia andar nas mãos de um colega? Tê-la-á lido só na idade adulta, ou foram outras obras, por estudar - ou igualmente esquecidas - a influenciarem-no? São interrogações a que não sabemos responder.

\section{OUTRA HISTÓRIA DO CARBONO}

É interessante notar que a história de um átomo de carbono, desta vez não personificado, foi retomada por Primo Levi (1919-1987) em «Carbono», último e breve conto de Il Sistema Periodico (1975, traduzido para português como «O Sistema Periódico», 1988). Segundo o autor, a ideia surgiu-lhe durante o internamento no campo de extermínio de Auschwitz (1944-45), onde escapou por pouco à morte. Pensara então que a história poderia dar um romance inteiro.

\section{O ÁTOMO DE EGA}

Ega/Eça não se compromete com a natureza química do seu átomo. Em nenhum ponto se diz se era de carbono ou de outro qualquer elemento. Permita-se-nos um exercício fútil: O excerto de Os Maias que se reproduz no início desta nota, leva a concluir que os elementos mais ajustados seriam o hidrogénio e o oxigénio. Ora, no final da descrição da morte do príncipe Franck (única parte do livro que Ega chega a escrever) lê-se:

"Ao findar, o Átomo exclamava, com a vasta solenidade de um cheio de órgão: «Assim arrefeceu, parou, aquele coração de herói que eu habitava; e evaporado o princípio de vida, eu, agora livre, remontei aos astros, levando comigo a essência pura desse amor imortal.»”.

Remontar aos astros significa escapar à atracção gravitacional terrestre. Como só o hidrogénio e o hélio saem continuamente da atmosfera para o espaço em quantidades significativas, podemos excluir o oxigénio, e o «átomo do Ega» tinha que ser de hidrogénio, o primeiro de todos os elementos, pela simplicidade, pela abundância, e por ser a principal matéria-prima das estrelas, fontes de radiação essencial e maternidades de elementos químicos [19].

\section{As MOLÉCULAS DE EC̣A}

O monumento a Eça de Queirós em Lisboa, no Largo Barão de Quintela, contém também um antropomorfismo, 
alegoria conforme ao gosto - masculino - da época: a Verdade é representada por uma semideusa de forma humana, mal coberta por uma túnica vaporosa (Figura 3). Sujeito a vandalismos ao longo dos anos (partiram-se muitos dedos e alguns braços à Verdade, vá lá saber-se porquê), o trabalho em pedra calcária de Mestre Teixeira Lopes acabou por ser substituído, em 2001, por uma cópia em bronze, guardando-se o original, desde então, no Museu da Cidade. Na inauguração do monumento, em Novembro de 1903, Ramalho Ortigão, «companheiro de trabalho e de estudo durante mais de trinta annos», afirmou, no seu discurso [20], que a estátua feminina, «casta e heroica Phrynêa», seria com mais justiça a imagem de «Lisboa intima», única das «grandes e belas cidades» que «retivera e seduzira» Eça de Queirós, e se tornara «o seu laboratorio de arte, o seu material d'estudo, a sua preoccupação de critico, o seu mundo d'escriptor». Embora fosse natural da Póvoa de Varzim, tivesse estudado no Porto e em Coimbra, e vivido em várias partes do mundo, incluindo Paris - onde morreu mas «onde nunca foi senão o extrangeiro, o hóspede, o emigrado (...)» -, Eça era «enraizadamente lisboeta, lisboeta até as mais intimas moleculas do seu organismo (...)».

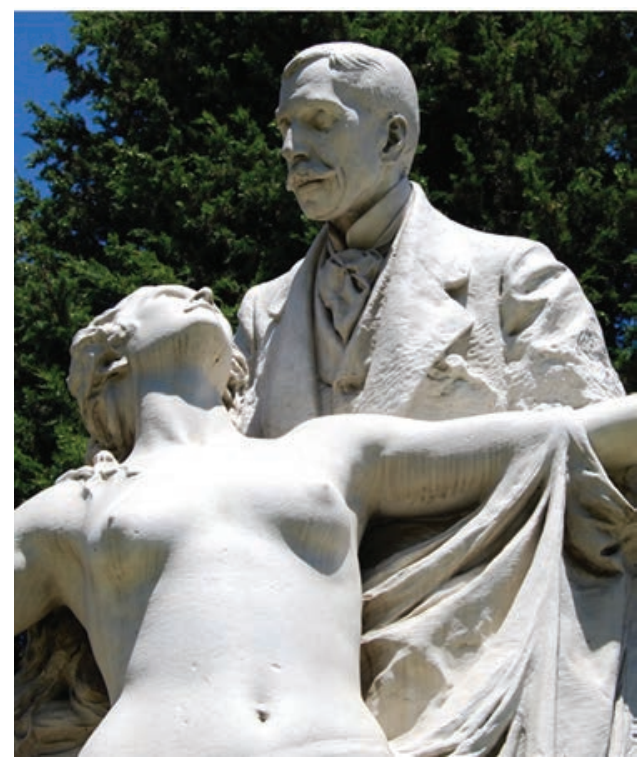

Figura 3 - Pormenor do monumento a Eça de Queirós, em Lisboa (entre 1903 e 2001 no Largo Barão de Quintela, desde então no Museu da Cidade), obra do escultor Teixeira Lopes (1866-1942). Tem por legenda o dístico d'A Relíquia: «Sobre a nudez forte da Verdade, o manto diaphano da Phantasia.»

\section{BiBLIOGRAFIA CITADA E NOTAS}

[1] Romance publicado no ano em que o autor completou 43 anos (morreria aos 54).

[2] Química (Boletim da SPQ) 60 (1996) 46

[3] Para além das Memórias dum átomo, publicaram-se nesta secção, entre 1994 e 1998 (números 52 a 68), mais quinze textos, referentes a obras de, entre outros, Manuel Bernardes, Camilo Castelo Branco, Ramalho Ortigão, Ferreira de Castro, Vitorino Nemésio e Rómulo de Carvalho/ António Gedeão.

[4] J. Perrin, “Les Atomes”, F. Alcan, Paris, 1913

[5] B. Bensaude-Vincent, C. Kounelis (ed.), "Les Atomes: une anthologie historique”, Presses Pocket, Paris, 1991
[6] Edward Neville da Costa Andrade (1887-1971), físico inglês de remota origem portuguesa, presenciou, em 1913, o seguinte episódio, passado num club londrino, logo após o jantar. Ainda à mesa, Eddington afirma - talvez provocadoramente - que os electrões eram conceitos muito úteis mas poderiam, de facto, não existir. Rutherford levanta-se de imediato e contrapõe com veemência: Não existem, não existem? - Pois se vejo os coitadinhos aqui à minha frente tão claramente como vejo essa colher! («Not exist, not exist - why I can see the little beggars there in front of me as plainly as I can see that spoon», in Rutherford at Manchester, J. B. Birks ed., Heywood \& Co., London, 1962). Só mais tarde se soube quão estranhas eram estas ondículas «pontuais» e dotadas de spin semi-inteiro.

[7] W. Heisenberg, "A imagem da Natureza na Física Moderna”, Livros do Brasil, Lisboa, s.d. (o original alemão é de 1955)

[8] B. Béguet (ed.), "La science pour tous, 1850-1914“, CNAM, Paris, 1990

[9] D. Raichvarg e J. Jacques, "Savants et ignorants, une histoire de la vulgarisation des sciences“, Seuil, Paris, 1991

[10] B. Béguet (ed.), "La science pour tous“, Réunion des musées nationaux, Paris, 1994

[11] Para além de "As Grandes Invenções”, de Figuier (Fig. 1), podem citar-se a “Astronomia Popular” (Lisboa, 1893) e "As Terras do Céu” (Lisboa, 1900), ambas de Flammarion, cujo tradutor foi Salomão Saragga (1842-1900), judeu português nascido em família abastada, amigo de Eça de Queirós, e um dos oradores censurados nas célebres Conferências do Casino. Alguns autores nacionais abalançaram-se a produção própria, por exemplo Fonseca Benevides, com “O Fogo" (Lisboa, 1866; 2. ${ }^{\text {a }}$ ed. 1869), Augusto F. Simões, com "Cartas da Beira-Mar” (Coimbra, 1867) e Andrade Corvo, com a “Chimica Popular” (Lisboa,1882). Num período anterior são de mencionar o Padre Teodoro de Almeida e Acúrcio das Neves.

[12] A investigação directa do interior da Terra pela abertura de poços muito profundos, e a perfuração de túneis de centenas ou milhares de km ligando dois pontos distantes da superfície terrestre, por exemplo Paris e o Rio de Janeiro, para uma ligação rápida (viagem sempre com a duração de 42 min) por um comboio gravitacional, foram tema de vários artigos e livros, incluindo o romance "Through the Earth” (1898), do americano C. Fezandié, veja-se M.N. Berberan-Santos, E.N. Bodunov e L. Pogliani, J. Math. Chem. 47 (2010) 990

[13] http://dossiers-flaubert.ish-lyon.cnrs.fr

[14] A compreensão do processo de nucleossíntese introduziu um elemento poético adicional nesta narrativa das origens. O nosso corpo é feito de restos de estrelas desaparecidas, de "poeiras de estrelas», na expressão feliz de Hubert Reeves (n. 1932).

[15] No título original dinamarquês (e também em inglês), o soldadinho é de estanho (tinsoldat, tin soldier). Diz-se no conto que se aproveitara uma colher velha para fazer os soldados. Mas usavam-se também ligas - tóxicas - de estanho e chumbo (por exemplo 1:2) nestas miniaturas, e daí os nomes em francês e português. Vem a propósito referir que «chumbar», na sua acepção estudantil, provém das mesmas ligas/soldas, tradicionalmente vazadas em juntas e encaixes para elimi- 
nar folgas e vazios, permitindo assim prender com firmeza (chumbar), por exemplo um varão de ferro a um bloco de pedra. Encontramos igual ideia noutro termo, mais recente, do léxico educacional, a temida e controversa retenção.

[16] B. de B. significa, muito provavelmente, Baron de Boucheporn. René-Charles-Félix Bertrand de Boucheporn (1811-1857), mencionado e elogiado no início do livro, foi um aristocrata e engenheiro formado na École Polytechnique, autor de algumas obras de geologia, e defensor de uma teoria catastrofista da história geológica (esta seria determinada por colisões esporádicas de cometas com a Terra). A "Histoire d'un atome”, publicada postumamente, - a instâncias da viúva? - é, em grande parte, uma tentativa de divulgação da teoria de Boucheporn, como se afirma numa nota (p. 93).

[17] Em francês, todos os elementos são, de facto, substantivos masculinos (note-se que em português há dois elementos femininos; em inglês são todos neutros, e em alemão existem elementos dos três géneros).

[18] Figura lendária medieval, condenada a vaguear pelo mundo até à consumação dos séculos (veja-se, por exemplo, o estudo de M. Massenzio, "La Passion selon le juif errant" (L’Echoppe, Paris, 2006).

[19] Veja-se, de John Rigden, o livro "Hydrogen, The Essential Element” (Harvard University Press, Harvard, 2002), em que se descreve a grande importância do hidrogénio em muitas das etapas da Física e da Química, do Big Bang ao final do séc. XX. Surpreendentemente, o autor não trata da descoberta do hidrogénio.

[20] “A Eça de Queiroz, na inauguração do seu monumento, realisada em Lisboa a 9 de Novembro de 1903”, Livraria Chardron, Porto, 1904

\section{Actualidades Científicas}

\section{ÁstaTO - O ELEMENTO MAIS RARO QUE OCORRE NATURALMENTE NA TERRA}

O ástato (At) foi descoberto por Dale R. Corson e seus colaboradores em 1940, depois de bombardearem um alvo de bismuto com partículas alfa (núcleos de átomos de hélio). O ástato tem número atómico 85 e existe na natureza exclusivamente como isótopo radioactivo, resultante do decaimento de elementos mais pesados. O isótopo mais estável deste elemento tem apenas 8,1 horas de semi-vida. Existe um grande interesse no ástato devido às suas propriedades de decaimento por emissão de radiação alfa, que fazem dele ideal para a terapia de cancros e de lesões superficiais da pele.

Através de experiências realizadas no ISOLDE (separador de massa do CERN - Organização Europeia para a Pesquisa Nuclear) foi possível determinar pela primeira vez o potencial de ionização do átomo de ástato. Esta medição preenche uma lacuna na tabela periódica de Mendeleev, uma vez que o ástato era o único elemento presente na natureza para o qual esta propriedade fundamental era desconhecida.

De um modo geral, o conhecimento da primeira energia de ionização de um átomo, vista como a energia de ligação do electrão de valência mais externo, é tão importante para a reactividade química de um elemento como para a estabilidade das suas ligações em compostos químicos.

O conhecimento do valor experimental do potencial de ionização do átomo de ástato é importante na previsão das propriedades nucleares e químicas dos elementos super-pesados, em particular o elemento 117, que lhe sucede no grupo 17 da Tabela Periódica.

(adaptado de "Scientists Uncover Fundamental Property of Astatine - Rarest Naturally Occurring Element On Earth”, http://www.sciencedaily.com/releases/2013/05/130514112735.htm?utm_source=feedburner\&utm_ medium=email\&utm_campaign=Feed\%3A+sciencedaily+\%28ScienceDaily\%3A+Latest+Science+News\%29)

António Mendonça (mendonca@ubi.pt)
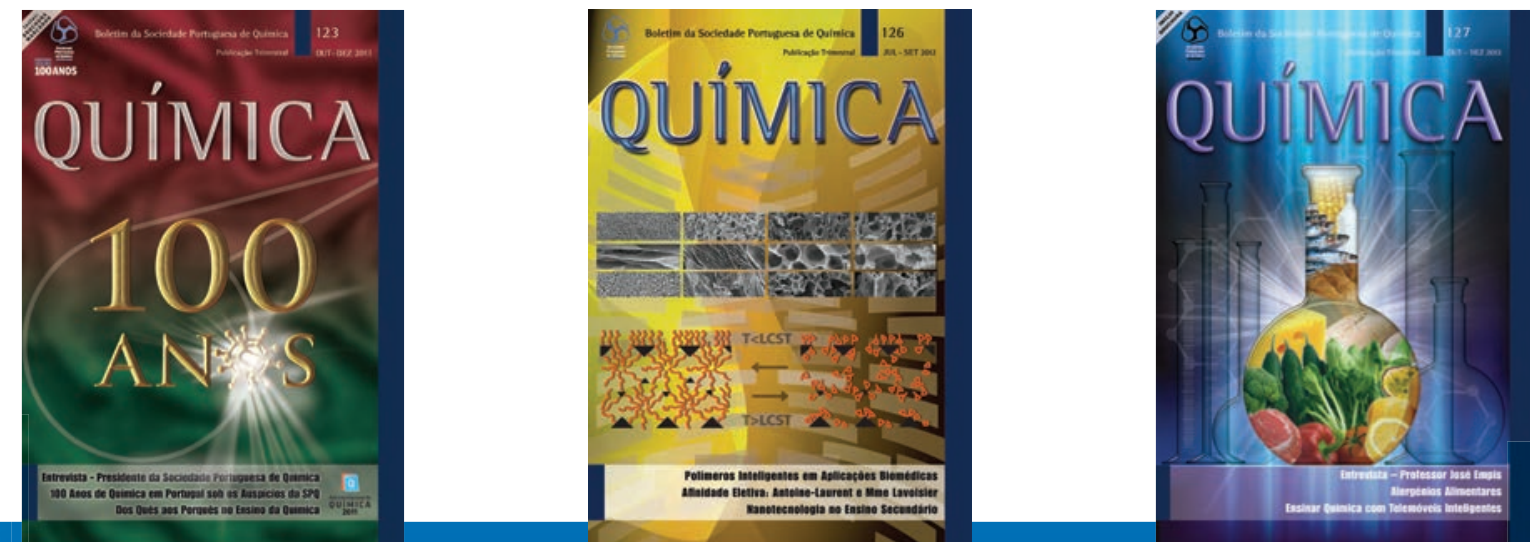
